\title{
Simon Hudson et Louise Hudson, Golf Tourism
}

Goodfellow Publishers, 2009, 290 pages

Patrick Legohérel

\section{OpenEdition \\ Journals}

Édition électronique

URL : http://journals.openedition.org/tourisme/493

DOI : 10.4000/tourisme.493

ISSN : 2492-7503

Éditeur

Éditions touristiques européennes

\section{Édition imprimée}

Date de publication : 1 décembre 2011

Pagination : 116-117

ISSN : 2109-5671

\section{Référence électronique}

Patrick Legohérel, «Simon Hudson et Louise Hudson, Golf Tourism», Mondes du Tourisme [En ligne], 4 | 2011, mis en ligne le 30 septembre 2015, consulté le 22 septembre 2020. URL : http:// journals.openedition.org/tourisme/493 ; DOI : https://doi.org/10.4000/tourisme.493

Ce document a été généré automatiquement le 22 septembre 2020.

\section{$\Theta \Theta \Theta \Theta$}

Mondes du tourisme est mis à disposition selon les termes de la licence Creative Commons Attribution - Pas d'Utilisation Commerciale - Pas de Modification 4.0 International. 


\section{Lecture critique}

\section{Simon Hudson et Louise Hudson, Golf Tourism}

Goodfellow Publishers, 2009, 290 pages

Patrick Legohérel

\section{RÉFÉRENCE}

Simon Hudson et Louise Hudson, Golf Tourism, Goodfellow Publishers, 2009.

1 L'ouvrage Golf Tourism, de Simon et Louise Hudson, propose une approche complète des thématiques golf, tourisme et management. Il est structuré en dix chapitres. La première partie (chapitres 1 à 4) est consacrée à la double présentation du golf (le produit golf, le marché, le joueur-golfeur-client) et du tourisme. Le chapitre 2 présente notamment les tendances comportementales (telles que la personnalisation, la recherche du bien-être, la recherche d'expérience...) qui exercent une influence sur la consommation des produits golfiques et touristiques. Le chapitre 4 aborde la problématique du développement des golfs, soulevant diverses questions telles que les types de golf et leur finalité économique (exemple : golf et programmes immobiliers) ou l'aménagement du territoire - le golf comme opportunité de développement, et ses limites (saturation, problèmes environnementaux, spéculation foncière...). Les problématiques de management et de marketing sont abordées dans les chapitres 5 (management), 6 (marketing) et 7 (chapitre dédié à la communication). Le chapitre 8 traite d'un aspect spécifique : l'organisation d'événements liés à l'activité golfique. Une dernière partie conduit le lecteur à une réflexion concernant le management de l'activité golfique dans un contexte touristique: le chapitre 9 traite de l'impact économique, environnemental et social du golf touristique. Enfin, le chapitre 10 propose des ouvertures et des pistes de réflexion quant à l'avenir du golf touristique.

De nombreux cas (environ 40) illustrent les thématiques abordées et renforcent la dimension professionnelle et opérationnelle de l'ouvrage. Les cas sont, pour la plupart, 
des espaces ouverts aux professionnels leur permettant de s'exprimer (interview), de présenter des données, de décrire de façon détaillée des sites, des produits, des expériences sportives et touristiques.

3 Nous pouvons regretter la place trop restreinte accordée à la dimension managériale (management et marketing). À l'heure où les entreprises golfiques cherchent à devenir des centres de profit efficients, et à sortir du champ étroit d'une activité sportive, sans objectif économique, un approfondissement des méthodes de gestion des structures golfiques aurait été appréciable. Les thèmes présentés dans les chapitres 4 (management) et 5 (marketing) sont importants (les questions de structure de coût, les sources de revenu, la gestion commerciale, la gestion des ressources humaines, le choix du système de management en réseau commercial ou en gestion indépendante, la maintenance et le greenkeeping...), mais ces questions sont abordées de façon trop superficielle et auraient mérité un approfondissement.

4 L'ouvrage s'inscrit dans une perspective internationale. Les disparités entre les pays (marchés) restent fortes (approche culturelle et rapport au golf, niveau de développement du golf, image du golf, développement touristique du marché, lien golf et tourisme...). L'ouvrage souligne ces écarts; par exemple le chapitre 2 propose des données économiques, sociodémographiques et comportementales permettant de différentier le touriste-golfeur à travers différents marchés. Cependant, les disparités, notamment culturelles, auraient pu être soulignées avec plus de force dans l'ouvrage.

Globalement, le point fort de l'ouvrage est de proposer un premier panorama complet des thématiques golf et tourisme, en pleine croissance. L'ouvrage constitue une source d'information et de réflexion appréciable tant pour les étudiants que pour les professionnels du golf et/ou du tourisme, en vue de contribuer au développement économique de structures sportives et touristiques. 